\title{
SUBCUTANEOUS AND CUTANEOUS MELANINS IN RHABDOMYS COMPLEMENTARY ULTRAVIOLET RADIATION SHIELDS
}

\author{
Robert M. Timm And L. Henry Kermott
}

\begin{abstract}
We describe the pigmented tissue layer covering the skull of Rhabdomys pumilio and test the hypotheses that it is melanin and that it functions in absorption of ultraviolet solar radiation. The parietals were covered by a dark tissue layer with smaller amounts of pigment extending over the frontals and nasals. Pigment granules also were observed in many skeletal muscles. Histologically, these tissues contained granules that stained black with hematoxylin and eosin, and silver impregnation. Spectrographic absorbency scans of pigment on the skull and in the skin showed two pigment layers absorbing maximally at different ultraviolet wavelengths. We suggest that both pigments are melanin acting in a complementary manner to provide an effective central nervous system radiation shield in Rhabdomys.
\end{abstract}

The adaptive significance of pigmented skin in mammals has long been debated; suggested functions include radiation exchange, absorption of heat, optimization of vitamin D synthesis, protection from nutrient photolysis, camouflage, and protection from radiation (Branda and Eaton, 1978; Daniels et al., 1972; Hamilton, 1973; Hunsaker and Johnson, 1959). Furthermore, pigment in skin may serve more than one function, and it may be difficult to distinguish between primary and secondary functions. Melanin is the most common dark pigment in skin, has been found in numerous species of vertebrates, and is an effective ultraviolet radiation screen. Porter (1967) demonstrated the absorption and reflectance capabilities of melanin in vertebrate tissues. He showed that the melanized peritoneum of the body wall of several species of lizards is an effective shield against ultraviolet radiation, and that the heavily-pigmented skin of antelope ground squirrels (Ammospermophilus leucurus) is an effective radiation shield.

In addition to a pigmentation within the skin, mammals of five genera possess a layer of melanistic tissue over the skull. Hill (1942:210) first noted that "the periosteum covering the roof of the skull was heavily black-pigmented in the rats of the genera Arvicanthis, Rhabdomys, Lemniscomys, and Pelomys ... while in other rats, chiefly nocturnal in habits, no pigment was seen." Hill concluded that the black pigment covering the skull was an adaptation to prevent "sun stroke" in these closely related, diurnal, African murids. Gardner and Wilson (1971:855) described a similar layer of melanistic tissue covering the skull of the Honduran white bat, Ectophylla alba (Chiroptera: Phyllostomatidae), and suggested that it "would intercept ultraviolet solar radiation potentially harmful to the brain." The four genera of murids that possess this pigmented layer are apparently all diurnal (Christian, 1977; Hill, 1942; Shortridge, 1934; Smithers, 1971); Ectophylla is nocturnal.

We selected the African striped field mouse, Rhabdomys pumilio (Rodentia: Muridae), for studying the function of the pigmented layer over the skull. Rhabdomys is widely distributed from southern South Africa north to Tanganyika, Kenya, and Uganda. It occurs in a variety of habitats, but most frequently in semi-dry bush and scrub habitats (Walker et al., 1975). We describe the pigmented periosteal tissue covering the skull of Rhabdomys, and test the hypotheses that the pigment is melanin and that it functions in absorption of ultraviolet solar radiation.

\section{METHODS}

Experimental animals were laboratory-reared offspring of a small colony (five pair) brought to this country in 1973 from Gorab, Maltahöhe District, Namibia (South West Africa) $\left(25^{\circ} 09^{\prime} \mathrm{S}, 16^{\circ} 31^{\prime} \mathrm{E}\right)$ by Rollin H. Baker. Five individuals were examined for melanin in the periosteum covering the skull, within the skin, and within the body musculature. Analyses were conducted on a double beam Cary 14 Recording Spectrophotometer. The spectrophotometer was used in the scanning mode with tungsten lamps for measurements in the visible range $(400-800 \mathrm{~nm})$ and hydrogen lamps in the ultraviolet range $(210-400 \mathrm{~nm})$. A simple device was constructed to mount whole tissue for placement within the light beam. We cut out the anterior and posterior faces of plastic spectrophotometer cuvettes within the region of light passage. Thus, there was no 
reflectance off the cuvette surface. Sheet aluminum was cut to fit snugly within the cuvette and a $6-\mathrm{mm}$ hole drilled at the level of the light beam. The spectrophotometer had a maximum beam width of $3 \mathrm{~mm}$, and care was taken to insure that the holders did not interrupt the beam. Tissue samples were cut to cover completely the 6-mm hole in the aluminum carrier, and were glued around the edge to the carrier with rubber cement. Both the aluminum holder and attached tissue were mounted at right angles to the light beam. Preliminary tests demonstrated that no light penetrated through the aluminum or was reflected around it; thus we measured only light passing through the tissue.

The overlying skin of the skull was reflected and the parietal bones removed with sharp scissors. Parietals were divided along the sagittal suture and adhering tissue was completely removed from the undersurface. All black pigment was scraped and flushed off one parietal, and the bone was mounted in the reference beam of the spectrophotometer. The other half, with the pigment covering intact, was placed in the sample beam. The resulting scanning curves therefore represent the difference spectrum due to the pigment alone.

Spectrophotometric examination of the dark pigmented skin presented a more difficult problem because we could not remove the insoluble pigment to produce a reference sample. Instead, we used skin covering the skull of a similarly-sized rodent, Peromyscus leucopus noveboracensis from Anoka County, Minnesota, in the reference beam. P. leucopus has no obvious dark skin pigmentation. The fur was shaved off both skin samples before they were mounted in the carriers. A single thickness of Peromyscus skin in the reference beam gave good results when scanning in the visible range. A double layer of Peromyscus skin was necessary during the ultraviolet scan to maintain readings within the range of the instrument, due to the strong absorbency of the dark Rhabdomys skin relative to the reference. Measurements are of transmitted light only.

Tissue samples of Rhabdomys also were examined histologically using formalin fixation and hematoxylin and eosin or silver impregnation staining. Attempts were made to dissolve the pigment in the following solvents: acetone, ethanol, ether, formalin, glacial acetic acid, methanol, toluene, unleaded gasoline, and water.

\section{RESULTS}

The amount of pigment covering the skull in Rhabdomys pumilio varied among individuals. In general the parietals were covered by a dark layer of pigmented periosteal tissue with light stippling extending over the frontals and nasals (Fig. 1). We did not attempt to measure individual variation in pigmentation because animals were of unknown age and differences observed might be developmental. However, individual variation included both the area and thickness of the pigmented layer. Scattered granules of pigment also were observed in many skeletal muscles, including external and internal obliques, pectoralis major, external intercostals, and thigh extensor muscles. Smaller amounts were seen in the rectus abdominus, gracilis, upper forelimb muscles, and extensor muscles along the vertebral column. We believe this to be the first report of melanin deposits in skeletal muscle in mammals. We observed no pigmentation in the peritoneum of Rhabdomys, as has been reported in reptiles by Porter (1967).

Spectrographs reported here are from a single representative individual (Field Museum of Natural History no. 122615). Shape and placement of curves obtained from different individuals were similar. Quantitative differences among samples occurred depending on the intensity of pigment present and our preparation technique. However, the shape and location of the maximum of the curve is the important factor for assessing the compounds present.

The ultraviolet spectrograph for the pigmented periosteal layer covering the skull of Rhabdomys was typical of aromatic hydrocarbons containing a benzene ring (such as melanin) (Fig. $2 a$ ). Maximum absorbency was in the range of $250-280 \mathrm{~nm}$ with the peak at $260 \mathrm{~nm}$. Minimum absorbency occurred from $290-380 \mathrm{~nm}$ with the low point at $310 \mathrm{~nm}$. Within the visible range, peak absorbency occurred at $415 \mathrm{~nm}$ and showed a steady decline through the visible spectrum to $800 \mathrm{~nm}$ (Fig. $3 a$ ).

Spectrographs for the pigmented skin of Rhabdomys showed high absorbency over the entire ultraviolet range (Fig. $2 b$ ), with the highest absorbency in the ranges of 210-275 $\mathrm{nm}$ and $305-350 \mathrm{~nm}$; within the latter range, the peak occurred at $320 \mathrm{~nm}$. Between these two ranges, absorbency was depressed at 275-305 nm. Beyond $350 \mathrm{~nm}$ absorbency tapered off sharply to $400 \mathrm{~nm}$. In the visible range peak absorbency occurred at $400 \mathrm{~nm}$ and declined rapidly to a low at $800 \mathrm{~nm}$ (Fig. 3b). 


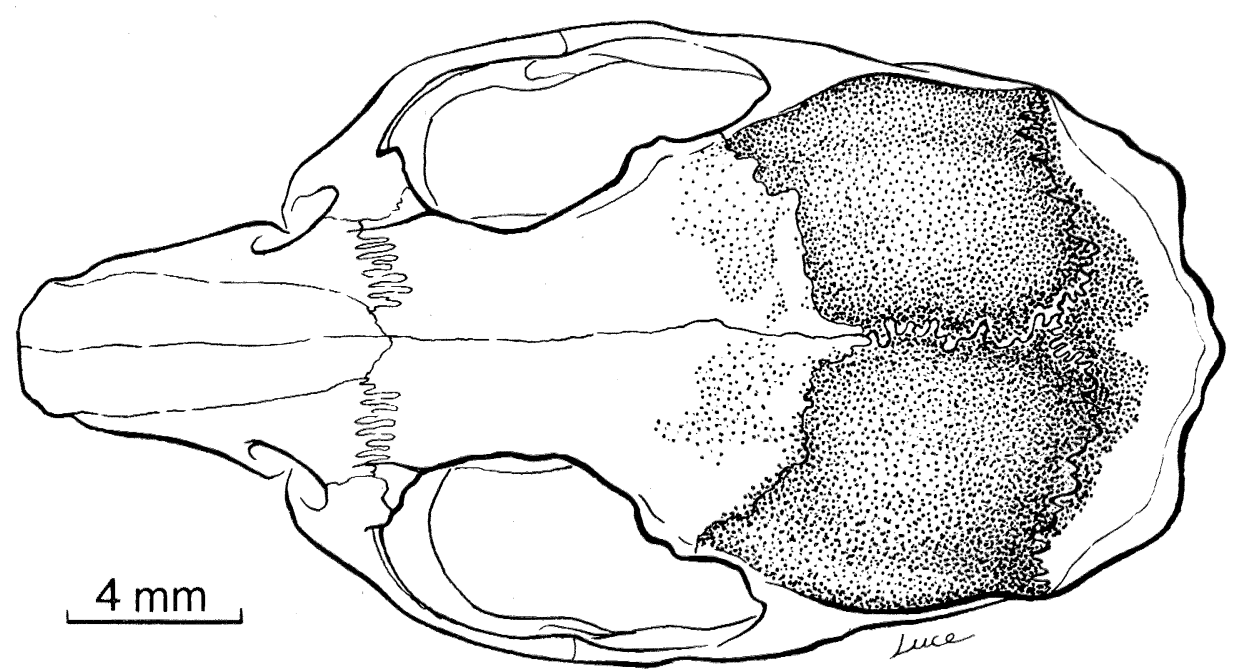

Fig. 1.-Dorsal view of the skull of an adult Rhabdomys pumilio, with the distribution of periosteal melanin indicated by stippling.

Microscopic examination of a section of parietal bone revealed a dense layer of black pigment granules in the outer periosteum. Pigment granules also were present in fatty tissue external to the periosteum. Numerous black pigment granules extended throughout the dermis; no pigment was seen in the thin epidermis. No pigment was seen in the fibers of the external abdominal obliques, but pockets of dark granules were present in the connective tissue surrounding muscle bundles.

We believe the dark pigmentation on the skull and in the skin and skeletal muscle is melanin. Grossly, the material was very dark, and, under the microscope, was granular and stained black with hematoxylin and eosin, and with silver impregnation. In addition, the material was insoluble in standard solvents and the spectrophotometric curves closely matched those of melanin standards.

\section{Discussion}

Many theories have been proposed to explain color in mammals (see Hamilton, 1973). Hair and skin colors probably function in thermoregulation, visual communication (both intra- and interspecific), concealment, and protection from ultraviolet radiation. Our results demonstrate that the absorptive capabilities of the pigmented tissue in Rhabdomys is consistent with that predicted for melanin, and that mammals with such a layer of tissue over the skull would receive significant protection from ultraviolet radiation. Melanin present in the periosteum is different from that in the skin. These two forms of melanin act complementarily, the periosteal layer screening out the shorter ultraviolet wavelengths and the skin layer screening out the longer ultraviolet wavelengths.

Melanin is not a single biological product, but a whole class of high molecular weight black or brown pigments formed by the polymerization of dihydroxyphenylalanine, usually bound to proteins (Harley-Mason, 1965; Metzler, 1977). Melanins are granular, insoluble pigments. It is well established that melanins are highly effective solar radiation shields, especially in the ultraviolet range. Radiant energy is absorbed by raising an electron from a lower energy state to a higher one. Different melanins have peak absorbencies in different ultraviolet ranges.

It is well known that ultraviolet radiation is destructive to mammalian tissues, especially DNA. In a comprehensive review of the significance of color to animals, Burtt (1979) stated that radiation damage is cumulative and that constant, low-intensity radiation can cause as much 


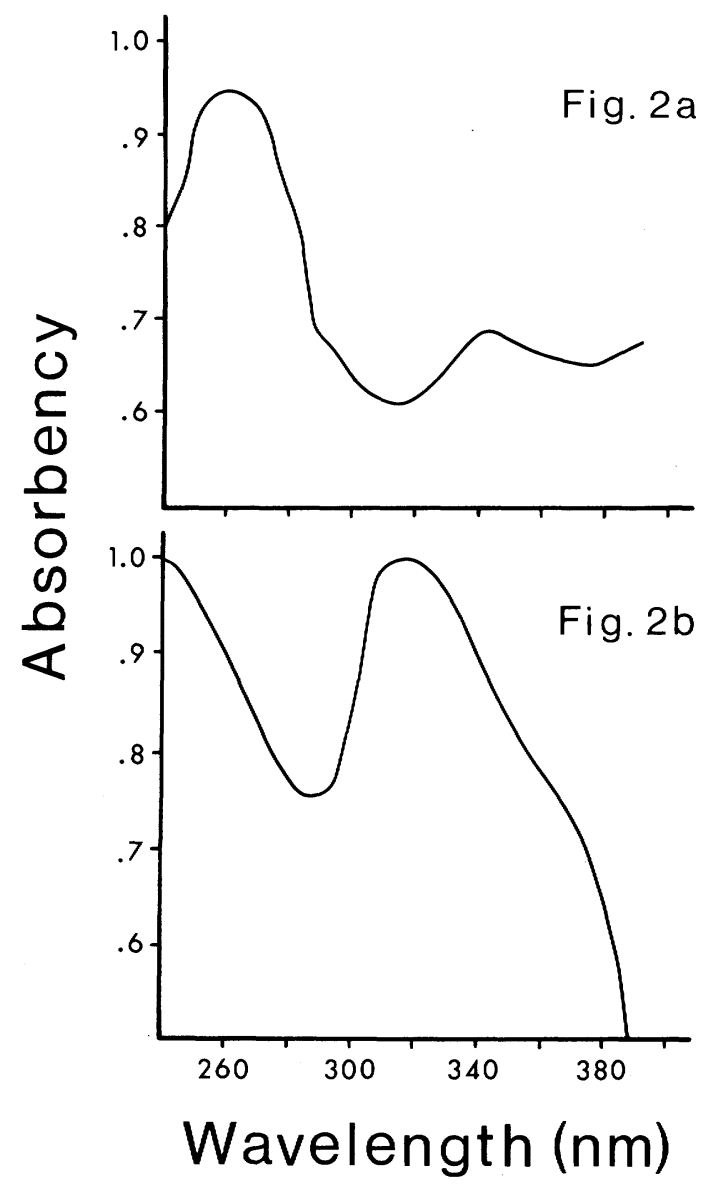

Fig. 2.-a) Absorbency curve in the ultraviolet range for melanin covering the skull in Rhabdomys. b) Absorbency curve in the ultraviolet range for Rhabdomys skin (Peromyscus skin served as the control).

damage as a single intense dose. Tissues most susceptible to radiation damage in vertebrates are nervous and reproductive tissue (Porter, 1967; Burtt, 1979). In humans, chronic exposure to the sun's ultraviolet radiation is thought to be the chief cause of nonmelanoma skin cancer, the most common type of carcinoma in the United States (see Setlow, 1974 and included references).

Ultraviolet radiation, while geographically variable, is most intense at low latitudes and high elevations (Walter, 1958). Murids that possess a melanistic skull cap (Arvicanthis, Lemniscomys, Pelomys, and Rhabdomys) are all found in areas of the African continent that receive high levels of ultraviolet radiation. Most small muroid rodents are primarily nocturnal, but Arvicanthis, Lemniscomys, Pelomys, and Rhabdomys, apparently are exceptions to this pattern (Choate, 1972; Christian, 1977; Smithers, 1971). Additionally, color patterns of the fur in both Lemniscomys and Rhabdomys suggest diurnal activity; both have distinctive dorsal stripes superficially resembling diurnal chipmunks and ground squirrels.

Ectophylla is found in the New World tropics, an area that also receives intense ultraviolet radiation. Why should the nocturnal Honduran white bat, E. alba, have subcutaneous melanin over the skull? Its fur is bright white, with little or no melanistic pigmentation; the body skin is thin and nonpigmented. Gardner and Wilson (1971:855) suggested that Ectophylla roosted under leaves of Heliconia (Musaceae), and that the melanistic layer of pigmentation covering 


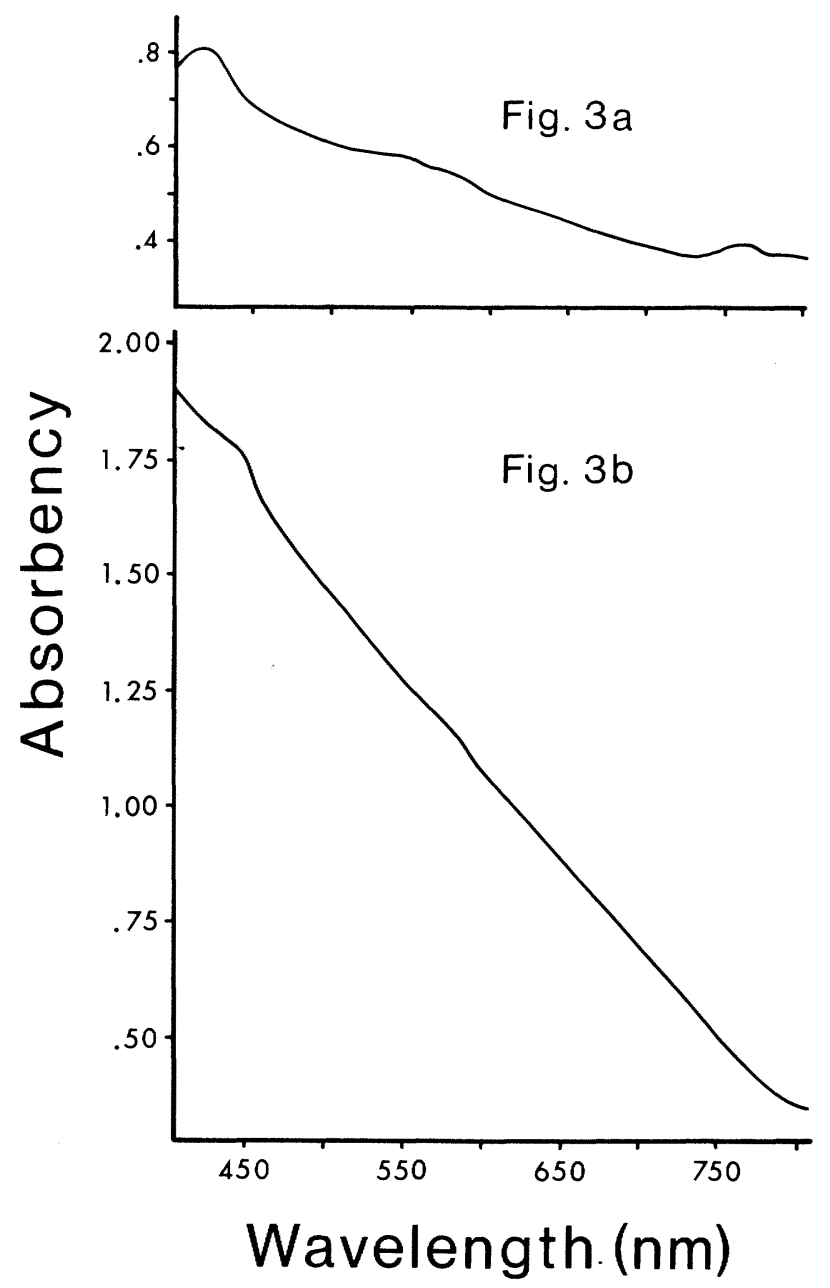

Fig. 3.-a) Absorbency curve in the visible range for melanin covering the skull in Rhabdomys. b) Absorbency curve in the visible range for Rhabdomys skin (Peromyscus skin served as the control).

the skull might serve to "intercept ultraviolet solar radiation." Timm and Mortimer (1976) found that E. alba modified the shape of Heliconia leaves to produce a tent for their diurnal roosting sites. In a survey of the species of Heliconia that Ectophylla selects, 14 of 26 were found in Heliconia imbricata, a species that grows only in forest clearings. The only protection roosting bats would have from ultraviolet radiation at such sites would be the thin layers of Heliconia leaves.

How then would a melanistic layer of tissue covering the skull protect bats hanging upsidedown under a leaf from solar radiation? These bats do not hang straight down from the midrib, but rather are curled tightly, with the top of the head pointed upwards (Fig. 4; Timm and Mortimer, 1976); hence, the melanistic skull cap could intercept ultraviolet radiation.

Rodents and bats may have resolved a common problem in a convergent manner; deposition of subcutaneous melanin over the skull. Upon close examination, the extracranial melanin deposits in Ectophylla are quite different from those found in the murid rodents. In all four genera of murids, the extracranial melanin lies as a dense layer directly on the skull within the perios- 
teum. In Ectophylla, melanin is deposited as scattered granulations above the cranial musculature, just beneath the skin.

An alternative hypothesis to melanin acting as an ultraviolet radiation shield is that the melanistic skull cap or melanin granules within muscular tissue has a thermoregulatory function (Hunsaker and Johnson, 1959). Melanins within the skin and hair may function in a thermoregulatory capacity, regulating absorbency of solar radiation. However, it is difficult to conceive how melanin beneath the skin could function in thermoregulation. Porter (1967:294) concluded that the pigmented peritoneum in reptiles was "insignificant in thermoregulation" because only a small fraction of the incident solar energy penetrated to that level.

Melanins in the skin, hair, feathers, and scales of vertebrates also play an important function in visual communication, both intra- and interspecifically. A communication function for subcutaneous melanin deposits must also be rejected as this melanin is simply not visible on the exterior of the animal. A fourth hypothesis is that there is no adaptative value to subcutaneous melanin, but that it is just a by-product of other physiological processes or functions, or of accidental occurrence. Since the melanistic skull cap effectively screens out ultraviolet radiation not absorbed by the skin, it seems unlikely that all subcutaneous melanin is simply an artifact. However, melanin deposited in skeletal muscle tissue would appear to provide insignificant protection against ultraviolet radiation passing through the body wall, because of the scattered nature of the pigmentation.

In summary, we have provided strong evidence that the subcutaneous layer of pigmented tissue in Rhabdomys contains melanin and that this melanic cap over the skull can provide a protective function in screening out ultraviolet radiation. Additionally, this melanin in the periosteum over the skull is a different form than the melanin within the skin covering the skull; these two melanins have different absorptive peaks for ultraviolet radiation, and they act in a complementary manner to provide an effective radiation shield in the diurnal Rhabdomys.

\section{ACKNOWLEDGMENTS}

We thank D. D. Baird, E. C. Birney, D. P. Christian, B. L. Clauson, K. Cliffer, G. Homison, S. Kirkwood, and $\mathrm{H}$. B. Tordoff for their helpful discussions and constructive comments on the manuscript. W. D. Schmid, R. P. Enever, and Sue-Chih Lee provided access to and logistic help on spectrophotometers under their care. D. Luce skillfully illustrated the skull. For assistance with the histological preparations, we are grateful to E. Haus of St. Paul Ramsey Hospital. R. Jenness provided us with the initial laboratory colony of Rhabdomys pumilio. We owe a special thanks to B. L. Clauson for continued assistance with all aspects of this project.

\section{Literature Cited}

Branda, R. F., and J. W. Eaton. 1978. Skin color and nutrient photolysis: an evolutionary hypothesis. Science, 201:625-626.

BurtT, E. H., JR. 1979. Tips on wings and other things. Pp. 75-110, in The behavioral significance of color (E. H. Burtt, Jr., ed.). Garland STPM Press, New York, 456 pp.

ChOATE, T. S. 1972. Behavioural studies on some Rhodesian rodents. Zool. Africana, 7:103-118.

Christian, D. P. 1977. Diurnal activity of the fourstriped mouse, Rhabdomys pumilio. Zool Africana, 12:238-239.

Daniels, F., JR, P. W. Post, and B. E. Johnson. 1972. Theories of the role of pigment in the evolution of human races. Pp. 13-22, in Pigmentation: its genesis and biologic control (V. Riley, ed.). 7th Internatl. Pigment Cell Conf., 682 pp.

Gardner, A. L., AND D. E. Wilson. 1971. A melanized subcutaneous covering of the cranial musculature in the phyllostomid bat, Ectophylla alba. J. Mamm., 52:854-855.
Hamilton, W. J., III. 1973. Life's color code. McGraw-Hill, New York, 238 pp.

Harley-Mason, J. 1965. Melanins. Pp. 254-257, in Comprehensive biochemistry (M. Florkin and E. H. Stotz, eds.). Amer. Elsevier Publ. Co., New York, 323 pp.

HiLl, J. E. 1942. A supposed adaptation against sun stroke in African diurnal rats. J. Mamm., 23:210.

HuNSAKER, D., II, AND C. JoHNSON. 1959. Internal pigmentation and ultraviolet transmission of the integument in amphibians and reptiles. Copeia, 1959:311-315.

Metzler, D. E. 1977. Biochemistry. Acad. Press, New York, 1129 pp.

Porter, W. P. 1967. Solar radiation through the living body walls of vertebrates with emphasis on desert reptiles. Ecol. Monogr., 37:273-296.

SetLow, R. B. 1974. The wavelengths in sunlight effective in producing skin cancer: a theoretical analysis. Proc. Natl. Acad. Sci., 71:3363-3366. 
Shortridge, G. C. 1934. The mammals of South West Africa. William Heinemann Ltd., London, 437 pp.

Smithers, R. H. N. 1971. The mammals of Botswana. Mus. Mem., Trustees Natl. Mus. Rhodesia, Salisbury, 4:1-340.

Timm, R. M., AND J. Mortimer. 1976. Selection of roost sites by Honduran white bats, Ectophylla alba (Chiroptera: Phyllostomatidae). Ecology, 57:385-389.

WALKER, E. P., ET AL 1975. Mammals of the world. Third ed. (J. L. Paradiso, ed.). The Johns Hopkins Univ. Press, Baltimore, 2:647-1500.

Walter, H. 1958. Der Zusammenhang von Hautfarbenverteilung und Intensität der ultravioletten Strahlung. Homo, 9:1-13.

Bell Museum of Natural History, University of Minnesota, Minneapolis, MN 55455 (present addresses: Timm: Division of Mammals, Field Museum of Natural History, Roosevelt Road at Lake Shore Drive, Chicago, IL 60605; Kermott, Biology Department, St. Olaf College, Northfield, MN 55057). Submitted 30 March 1981. Accepted 29 May 1981. 